\title{
Evaluation of Liquid Metal Embrittlement of Oxide Dispersion Strengthened Steel MA956
}

\author{
B.W. Baker ${ }^{1}$ and L.N. Brewer ${ }^{2}$ \\ ${ }^{1}$ Mechanical Engineering Department, United States Naval Academy, Annapolis, MD, USA \\ ${ }^{2}$ Mechanical and Aerospace Engineering Department, Naval Postgraduate School, Monterey, CA, USA
}

The Liquid Metal Embrittlement (LME) response of reactor steels is not well documented in current literature, and insufficient evidence exists to draw hypotheses on if or how the oxide dispersion strengthened steel MA956 will undergo LME in molten metal environments; however, data from the late 1970s and early 1980s gives insight into what conditions might promote LME [1-2]. Examples of material couples that cause LME include commercially available iron in molten lead which underwent LME, while higher purity iron did not. The other primary factors that determined an LME response were temperature of the embrittler and intimacy of contact between the metal and the embrittler. For this research, the task of determining MA956 susceptibility to LME is accomplished by establishing the most likely conditions for LME in U-bend exposure test and in situ slow strain rate testing (SSRT).

U-bend specimens of MA956 were prepared for exposure in molten lead in accordance ASTM G30-97 [3] and were fully submerged in $2.8 \mathrm{~kg}$ of $99.9 \%$ pure $\mathrm{Pb}$ for 300 hours at $350^{\circ} \mathrm{C}$. The solubility of oxygen in lead at this temperature is less than $0.1 \mathrm{appm}$. After exposure to molten lead, specimens were cleaned, sectioned, mounted, and metallographically prepared for microscopy and energy dispersive spectroscopy (EDS) analysis. The methods used to evaluate to LME by SSRT follow [4] and the principles are discussed in $[1,2]$. A miniature tensile specimen (length $=12.7 \mathrm{~mm}$, width $=5.08 \mathrm{~mm}$, and thickness $=1.09$ $\mathrm{mm}$ ) was pulled in tension in both liquid lead and liquid lead bismuth eutectic (LBE) and measurement of percent elongation and fracture mode determined by fractography were used to evaluate LME response.

The U-bend specimens did not fracture during exposure to molten lead (Figure 1a, b). After removal from the lead melting pot, the lead (and lead oxide) quickly solidified on the MA956 specimen (Figure 1b) and readily spalled off the sample with no cracking visible on any exterior surface of the specimens. Subsequent EDS analysis confirmed an outer layer of aluminum $\left(\mathrm{Al}_{2} \mathrm{O}_{3}\right)$ and inner layer of chromium $\left(\mathrm{Cr}_{2} \mathrm{O}_{3}\right)$ on the edges of the specimen (Figure 1c) and showed no discernible lead penetration past these protective oxide layers into the metal microstructure. SSRT of MA956 showed no significant change in tensile behavior from testing in air to the different molten metal environments. In each case, the stress strain curve of the control environment (air) was similar in characteristics to the test environment (lead at $328^{\circ} \mathrm{C}$ and $\mathrm{LBE}$ at $124^{\circ} \mathrm{C}$ ). Specifically the response in the elastic region was similar in each case, the specimen reached an ultimate tensile point in both environments, and the total elongation in each case was comparable between the control environment and the molten metal environment (Table 1). Fractography of MA956 specimens was consistent and showed comparable reduction in cross sectional area and a consistent failure surface across the specimen (Figures 2 and 3).

Based on these results, MA956 is not susceptible to LME in oxygen-saturated molten lead or LBE for the tested conditions, most notably temperatures near the melting temperature of the potential embrittler, and, although the tested conditions are limited in range, they were selected as the most likely conditions to cause LME based on current literature. 
References:

[1] M. G. Nicholas and C. F. Old, "Liquid-Metal Embrittlement," Journal of Materials Science, vol. 14, pp. $1-18,1979$.

[2] C. F. Old, "Liquid-Metal Embrittlement of Nuclear-Materials," Journal of Nuclear Materials, vol. 92, pp. 2-25, 1980.

[3] ASTM G30-97, "Standard Practice for Making and Using U-Bend Stress-Corrosion Test Specimens," 2009.

[4] ASTM G129-00, "Standard Practice for Slow Strain Rate Testing to Evaluate the Susceptibility of Metallic Materials to Environmentally Assisted Cracking," 2006.

(a)

(c)
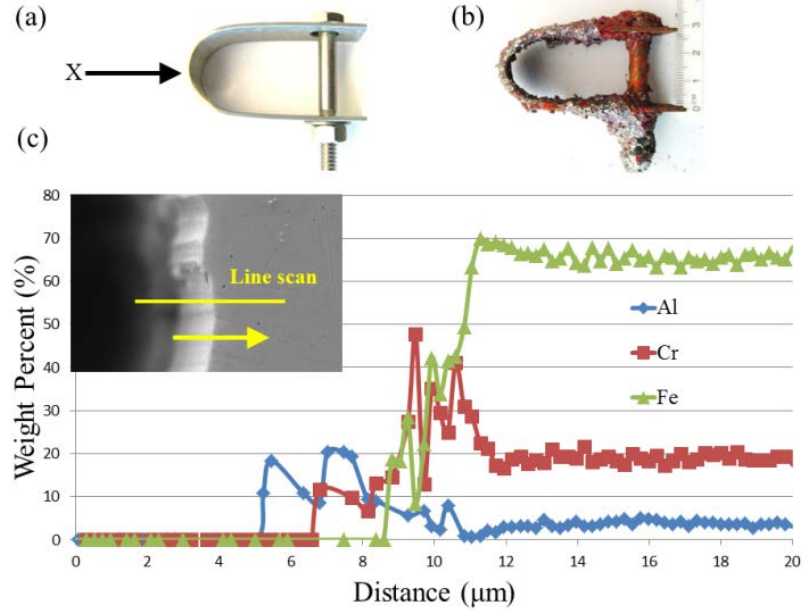

Figure 1. MA-956 U-bend specimen (a) prior to and (b) after exposure to molten lead. (c) Energy dispersive spectroscopy analysis of oxide layers after exposure to molten lead.
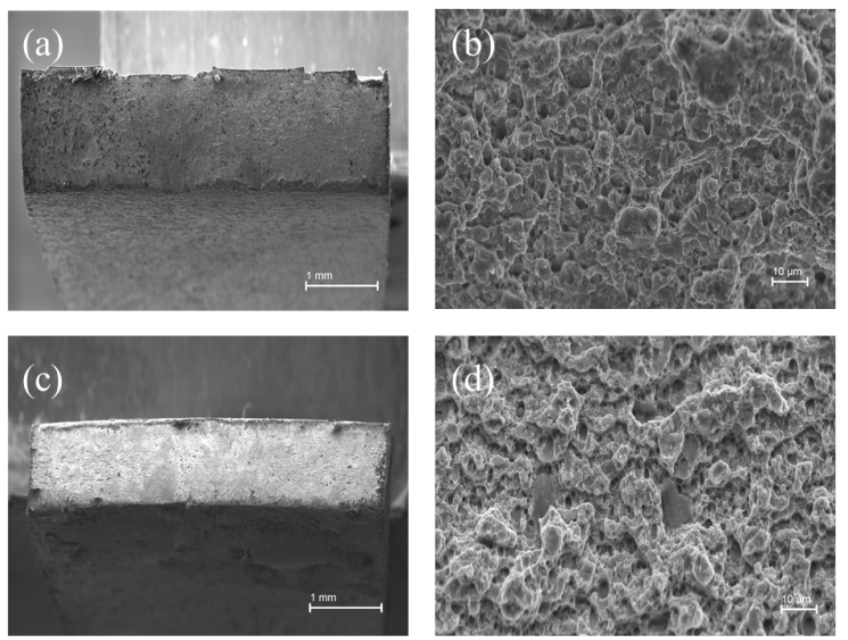

Figure 2. Fractography of MA956 SSRT specimens fractured at $328^{\circ} \mathrm{C}$ : (a) low magnification in air, (b) high magnification in air, (c) low magnification in $\mathrm{Pb}$, and (d) high magnification in $\mathrm{Pb}$.
Table 1. Summary of SSRT results for MA956.

\begin{tabular}{|c|c|c|}
\hline Environment & $\begin{array}{c}\text { Ultimate } \\
\text { Tensile } \\
\text { Strength } \\
(\mathrm{MPa})\end{array}$ & $\begin{array}{c}\text { Percent } \\
\text { Elongation (\%) }\end{array}$ \\
\hline $328^{\circ} \mathrm{C}$ Air & 823 & 10.9 \\
\hline $328^{\circ} \mathrm{C} \mathrm{Pb}$ & 860 & 10.7 \\
\hline $124^{\circ} \mathrm{C}$ Air & 938 & 10.9 \\
\hline $124^{\circ} \mathrm{C}$ LBE & 926 & 11.1 \\
\hline
\end{tabular}
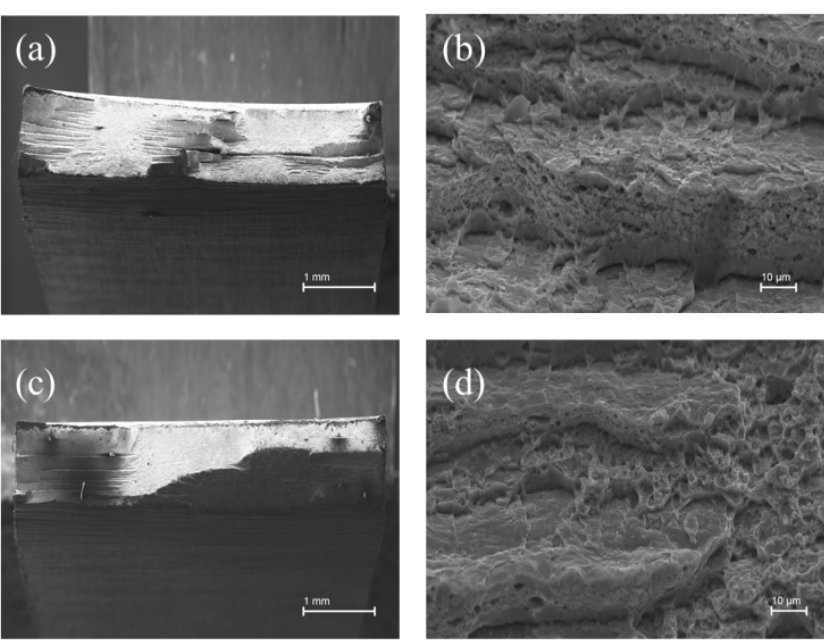

Figure 3. Fractography of MA956 SSRT specimens fractured at $124^{\circ} \mathrm{C}$ : (a) low magnification in air, (b) high magnification in air, (c) low magnification in LBE, and (d) high magnification in LBE. 